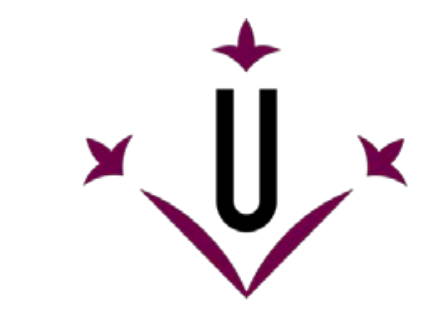

Universitat de Lleida

Document downloaded from:

http://hdl.handle.net/10459.1/65098

The final publication is available at:

https://doi.org/10.1007/s10343-016-0369-1

Copyright

(c) Springer-Verlag, 2016 
This is a pre-print version of the article A LiDAR-Based System to Assess Poplar Biomass published at the journal Gesunde Pflanzen on September 2016 at Volume 68, Issue 3, pp 155162 , with DOI 10.1007/s10343-016-0369-1. The final version of the article can be found at the publisher's website, Springer Link: https://link.springer.com/article/10.1007\%2Fs10343-0160369-1. Please, cite properly.

\title{
A LiDAR-based system to assess poplar biomass
}

Andújar, D. ${ }^{1}$, Escolà, A. ${ }^{2}$, Rosell-Polo, J.R. ${ }^{2}$, Sanz, R. ${ }^{2}$, Rueda-Ayala, V ${ }^{1}$., FernándezQuintanilla, C. ${ }^{3}$, Ribeiro, $\mathrm{A}^{1}$. and Dorado, J. ${ }^{3}$

${ }^{1}$ Centre for Automation and Robotics, (CSIC-UPM), Arganda del Rey, 28500 Madrid, Spain

${ }^{2}$ Research Group on AgroICT \& Precision Agriculture, UdL, Lleida 25198, Spain

${ }^{3}$ Institute of Agricultural Sciences, CSIC, Madrid 28006, Spain.

dionisioandujar@hotmail.com

\begin{abstract}
This study evaluated the capabilities of a LiDAR-based system to characterize poplar trees for biomass production. The precision of the system was assessed by analyzing the relationship between the distance records and biophysical parameters. The terrestrial laser scanner (TLS) system consisted of a 2D time-of-flight LiDAR sensor, a gimbal to dynamically stabilize the sensor and a RTK-GPS to georeference its location and, subsequently, the sensor data. The sensor and its stabilizer were fixed facing downwards, on a metal frame designed for this purpose. Then, it was mounted on an all-terrain vehicle to perform 2D scans in planes perpendicular to the travel direction. Distances between the sensor and the surrounding objects had a high spatial resolution, providing high density 3D point clouds. Results on the reliability of the LiDAR system to estimate plant height showed a significant relationship between the sensor readings and actual poplar height and biomass data. In addition, tree biomass and tree volume were properly estimated in the point cloud. Regression analysis showed significant estimates of 0.79 and 0.89 for biomass and volume, respectively. These results reveal the potential of the LiDAR sensor to estimate both, plant height and plant biomass. This sensor's capability, added to its relative low cost, fast reaction, and the high number of readings per second consolidate the ideal system for estimating the productivity of biomass in energy crops.
\end{abstract}

Keywords: Energy crops, productivity assessment, terrestrial LiDAR, plant structure 
This is a pre-print version of the article A LiDAR-Based System to Assess Poplar Biomass published at the journal Gesunde Pflanzen on September 2016 at Volume 68, Issue 3, pp 155162 , with DOI 10.1007/s10343-016-0369-1. The final version of the article can be found at the publisher's website, Springer Link: https://link.springer.com/article/10.1007\%2Fs10343-0160369-1. Please, cite properly.

\section{Ein LiDAR-basiertes System zu bewerten Pappel Biomasse}

\section{Zusammenfassung}

In dieser Studie wurden die Fähigkeiten eines LiDAR-basiertes System zu charakterisieren Pappeln Bäume für Biomasseproduktion untersucht. Die Genauigkeit des Systems wurde durch Analyse der Beziehung zwischen dem Abstand Aufzeichnungen und biophysikalischen Parameter bewertet. Der terrestrische Laserscanner (TLS) System bestand aus einem 2D Flugzeit LiDAR-Sensor, eine Kardanische Aufhängung für dynamische Stabilisierung des Sensors, und einen RTKGPS für Georeferenzierung innerhalb des Feldes und anschließend die Sensordaten. Der Sensor und seine Stabilisator wurden nach unten feste zugewandt, auf einem für diesen Zweck ausgelegt Metallrahmen. Dann wurde es auf einem Geländefahrzeug montiert. Von hier, es nahm 2D Scanner Daten in Ebenen senkrecht zur Fahrrichtung. Die Entfernungen zwischen dem Sensor und der umliegenden Objekte hatte eine hohe räumliche Auflösung, die eine höhere Dichte von 3D-Punktwolke bietet. Die Ergebnisse auf die Funktionsfähigkeit des LiDAR Systems um die Pflanzenhöhe zu bestimmen zeigten eine starke Beziehung zwischen die Sensormesswerten und den tatsächlichen Pappel Höhe und Biomasse Daten. Darüber hinaus Baum Biomasse und Baumvolumen wurden in der Punktwolke richtig geschätzt. Die Regressionsanalyse zeigte signifikanten Schätzungen von 0,79 bzw. 0,89 für Biomasse und Volumens. Diese Ergebnisse zeigen deutlich das Potential des LiDAR-Sensor um beide, Pflanzenhöhe und pflanzlicher Biomasse abzuschätzen. Diese Sensorkapazitäten, zusätzlich mit seiner relativ geringen Kosten, schnelle Reaktion, und die hohe Zahl der Messwerte pro Sekunde, verfestigen das ideale System um die Produktivität von Biomasse in Energiepflanzen zu bewerten.

Schlüsselwörter: Energiepflanzen, Abschätzung der Produktivität, terrestrische LiDARSensor, Pflanzenstruktur 
This is a pre-print version of the article A LiDAR-Based System to Assess Poplar Biomass published at the journal Gesunde Pflanzen on September 2016 at Volume 68, Issue 3, pp 155162 , with DOI 10.1007/s10343-016-0369-1. The final version of the article can be found at the publisher's website, Springer Link: https://link.springer.com/article/10.1007\%2Fs10343-0160369-1. Please, cite properly.

\section{Introduction}

Characterization of tree structure is of high importance, because detailed information about plant phenotyping leads to an adequate management of tree crops. Geometrical characterization allows improvement of pesticide application, fertilization and irrigation programs, which can help to achieve the main goal of a high crop yield. Geometric characteristics of trees are directly related to their growth status and productivity. This information is widely used for yield estimation and tree crop management. Characterization of tree geometry could be completed manually or through automatic processes. For manual processes, data of averaged crop height and crop width are measured with a metric tape and from those values, canopy volume can be estimated. This methodology has been generally used in connection with spraying of fertilizers or chemicals. However, manual measurements assume homogeneous volume in relation to height and width.

Leaf area index (LAI) and total leaf area can also be manually measured. However, this task is time consuming since it requires laboratory measurements of every individual leaf surface, in addition to the disadvantages of being a destructive method. Moreover, the values obtained from single samples should not be extended to the whole field, as the variability between trees is not considered. The use of sensors in an automatic data acquisition process could improve the measurements. This enhancement would lead to models which must simulate the real plant structure. Hence, acquisition of accurate models would contribute to a better crop management. The use of sensors for crop characterization is widely known. RGB sensors have been used for several purposes, such as phenology monitoring (Crimmins \& Crimmins, 2008), vegetation structure description (Cescatti, 2007), biomass and fertilization status (Hunt et al., 2005), crop yield estimation (Diago et al., 2012) or weed crop discrimination (Weis et al., 2008). The use of RGB cameras with image-processing software can detect objects and measure plants accurately, quickly and non-destructively (Yamamoto et al., 2012).

Wang et al. (2013) developed an image-processing system for crop yield estimation in apple orchards. They were able to discriminate red and green apples using RGB images. 
This is a pre-print version of the article A LiDAR-Based System to Assess Poplar Biomass published at the journal Gesunde Pflanzen on September 2016 at Volume 68, Issue 3, pp 155162 , with DOI 10.1007/s10343-016-0369-1. The final version of the article can be found at the publisher's website, Springer Link: https://link.springer.com/article/10.1007\%2Fs10343-0160369-1. Please, cite properly.

Andújar et al. (2013) developed a method for discriminating vegetation and soil in a cereal crop based on RGB image processing, demonstrating that RGB cameras are a high resolution tool with optimal efficiency. This type of cameras have advantages compared with other sensors, such as an easy processing system and a low acquisition cost. Other sensors using NDVI technology have been used in precision farming in tasks related to crop nitrogen management and plant stress detection (Tremblay et al., 2009). NDVI sensors are active, equipped with a light source in the red and near infrared wavelengths, allowing them to work under conditions without light. The use of ultrasonic sensor for tree characterization has been explored by many authors (Zaman et al., 2001; Andújar et al., 2011; Llorens et al., 2011; Rosell et al., 2012). Ultrasonic sensors transmit high frequency sound waves towards an object and sense the reflected echo. The distance between the sensor and the object is then calculated by measuring the time difference between the transmission and the reception of the waves.

LiDAR technology (Light Detection and Ranging) has been widely used in some agricultural and forestry applications, such as estimation of cereal crop volume (Saeys et al., 2009; Andújar et al., 2013) and electronic measurement of canopy dimensions in woody crops (Richardson et al., 2009). The sensor is based on a remote sensing technique that measures the time a laser pulse takes between the sensor and an impacted object. The light used by LiDAR is usually near-infrared radiation for plant studies. This radiation is reflected by the plant structure and is returned to the sensor. The lapse between transmission and reception is measured by the time-of-flight method, in order to calculate the distance between the sensor and the reflecting object. Algorithms developed on the point clouds allow the digital reconstruction of tree structure (Rosell et al. 2009). These systems can also be used to characterize and quantify the time scale variations of canopy structure along a cropping season.

Two-Dimensional Terrestrial LIDAR (2D TLS) collect two dimensional sweeps in a measured plane. A third dimension is obtained by displacing the sensor in a perpendicular movement to the scanning plane (Rosell et al, 2009b; Walklate et al., 2006). 3D TLS Tripod-Mounted sensors are applied to automatically characterize 3D structures. The sensor captures hundreds of thousands of accurate data points, representing the complete 
This is a pre-print version of the article A LiDAR-Based System to Assess Poplar Biomass published at the journal Gesunde Pflanzen on September 2016 at Volume 68, Issue 3, pp 155162 , with DOI 10.1007/s10343-016-0369-1. The final version of the article can be found at the publisher's website, Springer Link: https://link.springer.com/article/10.1007\%2Fs10343-0160369-1. Please, cite properly.

surface geometry of the measured structure. The laser automatically scans and rotates to produce a point cloud. Each data point consists of $\mathrm{x}, \mathrm{y}$ and $\mathrm{z}$ coordinates of the assessed surface. Moorthy et al. (2004) characterized individual tree crowns at olive tree plantations with a Laser Ranging and Imaging System (ILRIS-3D) sensor. They installed a 3D TLS tripod-mounted ILRIS-3D scanner to provide measurements of the olive crowns. In a grapevine biomass estimation study (Keightley and Bawden, 2010), a tripodmounted laser scanning provided the means to generate volumetric measures of plant structure and perennial woody tissue for the estimation of standing biomass in agronomic and natural ecosystems. Measurements from grapevine trunks and cordons were used to assess the accuracy of wood volume measured from laser scanning, as compared with volume derived from analog measurements. The study concluded that digital volumes were greater than those of analog volumes.

Using 3D scanner in order to cover big areas in agriculture has its limitations, while 2D LIDAR scanners facilitate a fast way to obtain $3 \mathrm{D}$ structural characteristics of tree plantations. 2D LIDAR measurements combined with the vehicle movement along the rows creates a 3D point cloud, which can be stored and visualized with a computer software. Three dimensional high density data are highly valuable when studying geometric parameters of trees. Applications of terrestrial laser scanner (TLS) sensors to obtain a point cloud corresponding to a plane or section of the crop, provide an appropriate tool to assess plant structure in a digital format of a massive data point clouds.

Characterization of energy crops is highly demanded, owing to their possible alternative energy source. Short rotation poplar (Populus spp.) plantations are considered as one of the most promising energy crop (Pérez-Cruzado et al, 2014). Poplar trees demand low inputs and are among the most productive woody energy crops (Börjesson 1999). New technologies are required to improve the agronomic management with the aim of increasing biomass yields, reducing cost of cultivation and improving environmental quality. Therefore, the main objective of this work was to evaluate the possibility of using a TLS system for estimating vegetative parameters, such as plant height, canopy volume or woody volume for biomass estimation in poplar trees, used as an energy crop. 
This is a pre-print version of the article A LiDAR-Based System to Assess Poplar Biomass published at the journal Gesunde Pflanzen on September 2016 at Volume 68, Issue 3, pp 155162 , with DOI 10.1007/s10343-016-0369-1. The final version of the article can be found at the publisher's website, Springer Link: https://link.springer.com/article/10.1007\%2Fs10343-0160369-1. Please, cite properly.

\section{Material and methods}

\subsection{Sampling System}

A data collection system was setup with a laser scanner model LMS-111 (SICK AG, Germany). The working principle was a 2D divergent laser scanner with a maximum field of view of $270^{\circ}$. The source of light was a pulsed infrared laser of $905 \mathrm{~nm}$ wavelength. The sensor had a selectable lateral resolution of between $0.25^{\circ}, 0.5^{\circ}$ and $1^{\circ}$, accuracy of $15 \mathrm{~mm}$ in a single-shot measurement and a $5 \mathrm{~mm}$ standard deviation in a range of up to 8 $\mathrm{m}$. The Time-of-Flight principle was employed to identify the distance between the laser scanner and the object. The sensor measured the time delay between an outgoing laser pulse and the returned beam, reflected by the impacted object. The LiDAR sensor had a source of light and a photodetector. The intensity of LiDAR light was modulated according to a sinusoidal signal . The photodetector detects the reflected beam coming back to the impacted object. The distance between the sensor and the impacted object is determined by measuring the phase shift between the emitted light beam and the reflected beam. An internal filter finds and deletes distance ambiguities. The sensor contains a rotating mirror that deflects the laser beam in different angles, following a plane to estimate the distance to different points. Thus, the sensor reads objects within a plane in angular scanning mode.

The sensor was located $200 \mathrm{~cm}$ above the ground, pointing downwards to the centre of a poplar row. A gimbal was mounted to dynamically stabilize the sensor. Readings were taken using an ATV-mounted LIDAR system that travelled along the crop in direction Z, parallel to the row, at constant speed between $5 \mathrm{~km} \mathrm{~h}^{-1}$ to $7 \mathrm{~km} \mathrm{~h}^{-1}$ in a straight line through the center of the inter-row area (Figure 1). The field-of-view of the LiDAR sensor was set to scan a ground width of $3 \mathrm{~m}$. The measurement configuration was set to $0.25^{\circ}$ angular resolution and a sampling frequency of $25 \mathrm{~Hz}$. Acquisition and processing software was developed using LabVIEW (National Instruments) graphical development environment. Sensor readings were transferred to a computer via Ethernet communication port. By distance extraction, a height profile was obtained containing all points where the laser beam impacted. The output was composed of vertical slices of the tree surface. Each vertical slice consisted of the intersection points between the laser beam and the tree. Distance between slices was about $10 \mathrm{~mm}$. 
This is a pre-print version of the article A LiDAR-Based System to Assess Poplar Biomass published at the journal Gesunde Pflanzen on September 2016 at Volume 68, Issue 3, pp 155162 , with DOI 10.1007/s10343-016-0369-1. The final version of the article can be found at the publisher's website, Springer Link: https://link.springer.com/article/10.1007\%2Fs10343-0160369-1. Please, cite properly.

LiDAR data and the positioning points were integrated into the coordinate system for obtaining the 3D structure of plants; this system was developed by using a RTK-GPS. Spatial coordinates were measured with respect to the LiDAR position. For each LiDAR position, the points intersected to create a slice corresponding to a full $180^{\circ} \mathrm{LiDAR}$ scan. The LiDAR position at each moment was determined by GPS measurements. Integration of vertical slices on the tree row, corresponding to different $\mathrm{Z}$ positions along the treerow line, provided a cloud of intersection points that creates a 3D point cloud of every impacted object within the field of view. In this way, although the LiDAR is a 2D laser scanner, the system created a 3D point cloud by moving the sensor in a parallel direction to the tree row. This procedure allowed the sensor data to be compared with manually measured values of crop biomass and tree height.
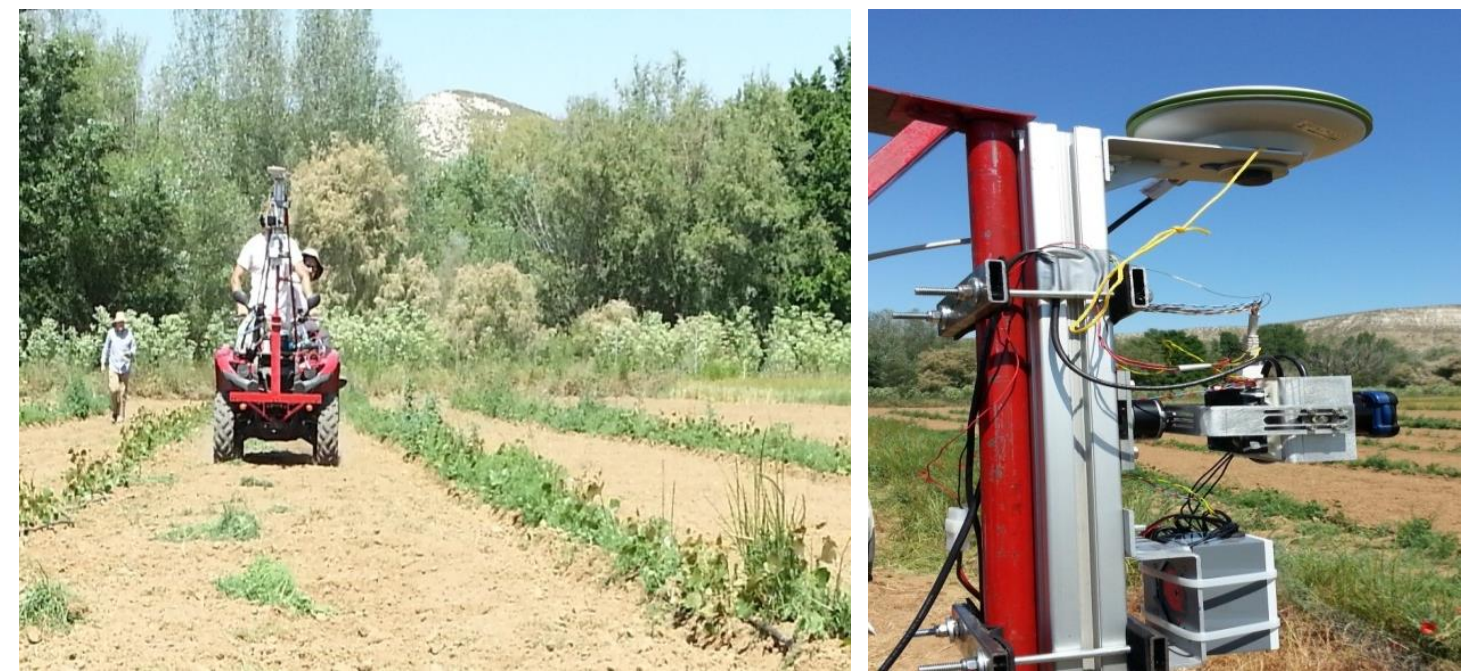

Figure 1. Image of the ATV with a structure to support the terrestrial LiDAR sensor, acquiring data on a field of poplar energy crop (left) and detail of the data acquisition system (right), ready to capture height readings.

\subsection{Site Location and Data Processing}

Field assessments were conducted in June 2014, during the first growing year of a poplar energy crop. The field trial was located in La Poveda Research Farm (Arganda del Rey, Madrid, Spain). The location is characterized by a Mediterranean climate with cold 
This is a pre-print version of the article A LiDAR-Based System to Assess Poplar Biomass published at the journal Gesunde Pflanzen on September 2016 at Volume 68, Issue 3, pp 155162 , with DOI 10.1007/s10343-016-0369-1. The final version of the article can be found at the publisher's website, Springer Link: https://link.springer.com/article/10.1007\%2Fs10343-0160369-1. Please, cite properly.

winters and hot and dry summers, thus requiring irrigation during both, spring and summer. Agricultural practices were the commonly applied on crops for biomass production. The key for high yield is assurance of water availability, weed control during establishment, and competition ability for light and temperature. As poplar is a perennial crop, ensuring ideal conditions at establishment will reap benefits at first and all subsequent harvests. Weed control was well done prior establishment. Eradication of all invasive perennial weeds was performed before transplanting. A systemic herbicide was applied with Oxifluorfen just before planting. The soil was sub-soiled to a depth of $40 \mathrm{~cm}$ to remove compaction, ploughed to a depth of $20 \mathrm{~cm}$ and left over-winter. Harrowing was done before planting and nitrogen was incorporated into the soil prior to transplanting. Poplars were planted as cuttings taken from one-year-old material that was harvested in January and stored at $-2^{\circ} \mathrm{C}$ and with a healthy bud about $1 \mathrm{~cm}$ below the top cut. Poplars were manually planted during spring 2014. The distance between poplar trees was $0.5 \mathrm{~m}$ and $3 \mathrm{~m}$ row spacing. Plants were irrigated utill the measuring time.

A total of 100, about 2 month old, poplar trees were evaluated on May 9th. Immediately after data acquisition, the trees were georeferenced in the field and actual height was measured. Afterwards, 10 one-year old poplar trees were also evaluated with LiDAR. Actual height was measured and plants were cut and processed in the lab for branch and leaf biomass determination. The LiDAR data were transformed from polar to cartesian coordinates and were saved with the associated GPS coordinates. As a result, a 3D point cloud was plotted. Subsequently, data of 100 poplar trees manually measured were plotted in the same file and compared with the LiDAR readings. Maximum LiDAR height was calculated by integration of maximum height in a $50 \mathrm{~cm}$ segment, corresponding to the intra-row space between trees. LiDAR height was plotted against biomass and actual poplar height. Tree volume was calculated for the one year old trees. Meshlab® was used for off-line processing of the point clouds. The software converted the point clouds to a solid mesh by sequential steps. Firstly, with the use of filters, points considered outliers and noise were removed from the point cloud. Secondly, each individual tree section was isolated and normals were calculated on the sub-sample. A Poisson algorithm was run for mesh reconstruction. Finally, from the solid model volume was calculated using computation of polyhedral Mass properties (Mirtich, 1996). 
This is a pre-print version of the article A LiDAR-Based System to Assess Poplar Biomass published at the journal Gesunde Pflanzen on September 2016 at Volume 68, Issue 3, pp 155162 , with DOI 10.1007/s10343-016-0369-1. The final version of the article can be found at the publisher's website, Springer Link: https://link.springer.com/article/10.1007\%2Fs10343-0160369-1. Please, cite properly.

\subsection{Statistical analysis}

The acquired data was processed statistically to identify the system capabilities for tree height and biomass estimation. Actual parameters were compared with those coming from the models created. The geometrical reliability of the LiDAR was assessed, considering a linear relationship between the actual plant heights and the height values measured with the LiDAR sensor. Simple linear regression was used to establish the relationship between LiDAR readings and actual values of structural parameters of trees and dry biomass. Prior to the regression analysis, correlation between variables was tested by an initial evaluation of bivariate relationships among variables. Linear regressions were analysed by Pearson's correlation coefficients between actual parameters of height and biomass and the LiDAR measured values of height and volume.

\section{Results and Discussion}

The relationship between results of scanning and manual measured tree parameters showed good values of agreement. The system was able to distinguish different heights of poplar trees. The actual tree height and extracted LiDAR values were highly similar. Results showed a great concordance between actual shape and 3D tree structural information. The high concordance of a sample with the physical dimensions of the data recorded with the LiDAR sensor is illustrated in Figure 2, showing good agreement of overall appearance (i.e., physical dimensions and shape) of the 3D digital plant structure and actual crop rows. The correlation coefficient obtained between manually measured height and those measurements from the 3D LiDAR point cloud was highly significant. Actual height and LiDAR acquired values in young trees were well estimated. A linear relationship between LiDAR measurements (LiDAR heights) and actual heights was found, demonstrating the accuracy of the method for tree height determination. This relation was significant at $99 \%$, with a good correlation between actual heights and LiDAR heights and an $\mathrm{R}^{2}=0.712$ (Figure $3 \mathrm{a}$ ). Comparison of point cloud and actual values showed a root mean squared error (RMSE) of $4.77 \mathrm{~cm}$. The case of young poplar trees is similar to annual crops. Andújar et al (2013) characterized maize and weed plants using a LiDAR-based system, concluding that the sensor readings were correlated with 
This is a pre-print version of the article A LiDAR-Based System to Assess Poplar Biomass published at the journal Gesunde Pflanzen on September 2016 at Volume 68, Issue 3, pp 155162 , with DOI 10.1007/s10343-016-0369-1. The final version of the article can be found at the publisher's website, Springer Link: https://link.springer.com/article/10.1007\%2Fs10343-0160369-1. Please, cite properly.

manually determined height values of different plants. The measurements were accurate enough to discriminate plant species.

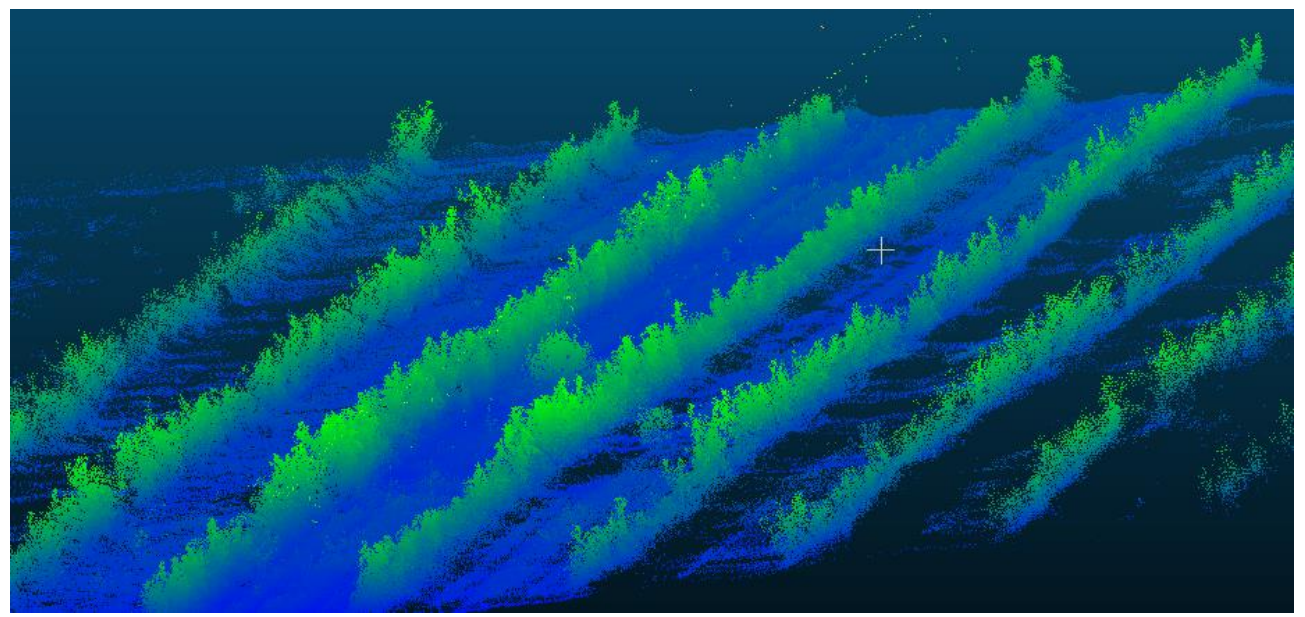

Figure 2. 3D raw model of poplar plantation obtained from the LiDAR-based system.

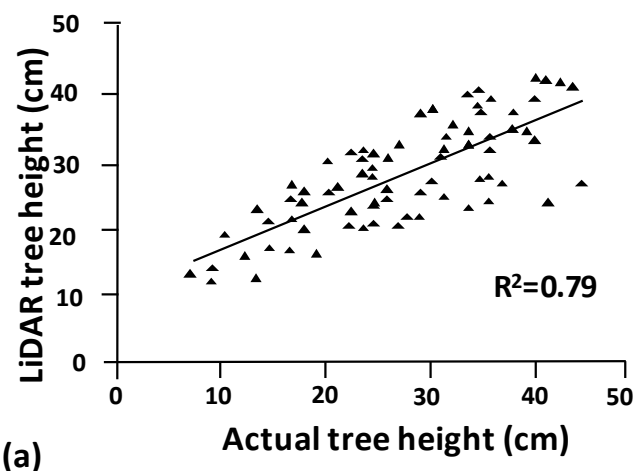

(a)

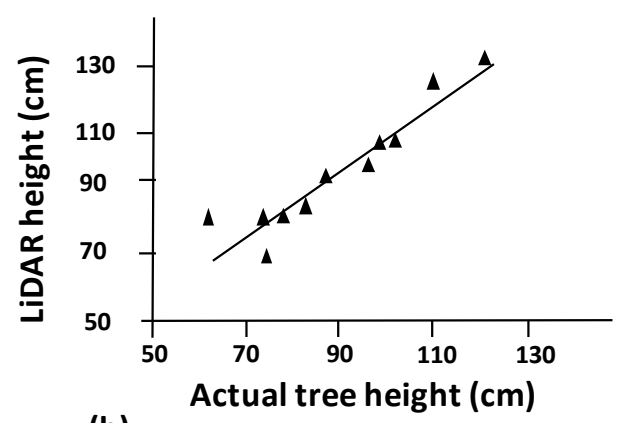

(b)

Fig. 3. Regression plot of tree height estimated by the LiDAR sensor against actual tree height measured manually for: a) young trees and b) one year old poplar trees.

Similarly, the case of one year trees showed significant correlations at 99\%. An R-squared value of 0.89 with an RMSE of $6.58 \mathrm{~cm}$ was obtained (Figure $3 \mathrm{~b}$ ). Some of top branches were not detected due to their small diameter of about 1 to $2 \mathrm{~mm}$ and the model tended to overestimate the maximum tree height. Dassot et al. (2010) showed similar results in branch detection in Beech trees. They revealed that a lot of tree axes were missing, particularly for the thin branching elements and especially at the top of the tree, where very thin geometries were not reached by the laser. Henning and Radtke (2006) by co- 
This is a pre-print version of the article A LiDAR-Based System to Assess Poplar Biomass published at the journal Gesunde Pflanzen on September 2016 at Volume 68, Issue 3, pp 155162 , with DOI 10.1007/s10343-016-0369-1. The final version of the article can be found at the publisher's website, Springer Link: https://link.springer.com/article/10.1007\%2Fs10343-0160369-1. Please, cite properly.

registration of errors between the lidar-derived diameter estimates and caliper measurements for bole sections below the base of live crown showed that the error did not exceed $2.1 \mathrm{~cm}$, with an average error $<1 \mathrm{~cm}$. Similarly, small branches and details could not be described with the same detail of big branches and leaves. These characteristics are mostly located in the top section of a tree, which agrees with the height model overestimation. Comparable results have been shown in the past with other sensors (Llorens et al., 2011), in which a significant correlation between actual characteristics and ultrasonic measurements was found. Although ultrasonic devices can extract plant information with high accuracy, they are not able to create a plane in a single reading. By contrast, the LiDAR sensor creates a plane. In addition, the resolution of LiDAR sensors is higher than that of ultrasonic sensors, due to the smaller laser beam footprints, high angular resolution and wider field of view.

Concerning tree biomass in relation to height, a highly significant correlation at $99 \%$ was observed. A linear relationship in the scatter plot of biomass versus measured height was found. Results for one year old trees showed that total plant biomasses were always well estimated with respect to tree height, with the data distributed along a line, and with variability increasing as biomass increases (Figure 4a). The regression showed a Rsquared of 0.79. A similar result was found for leaves and branch biomass. Values were always significant at $99 \%$. The linear relationships are plotted in figure $4 \mathrm{~b}$ and $4 \mathrm{c} . \mathrm{R}-$ squared values of 0.79 and 0.78 were found for leaves and branches, respectively, where even for the thin branching elements detection was accurate. Leaf biomass is directly related to LAI, defined as one-side leaf area per unit of ground area. Quantification of this parameter will help to manage agronomic tasks, such as irrigation or spraying. Thus, these results encourage the possibility to use this sensor for poplar management, starting at the crop establishment. In addition, use of a LiDAR sensor for on-the-go operations could help to determine drift due to wind speed and direction measuring the concentration of small droplets in the air (Gil et al, 2013), adapting the spraying technology. 

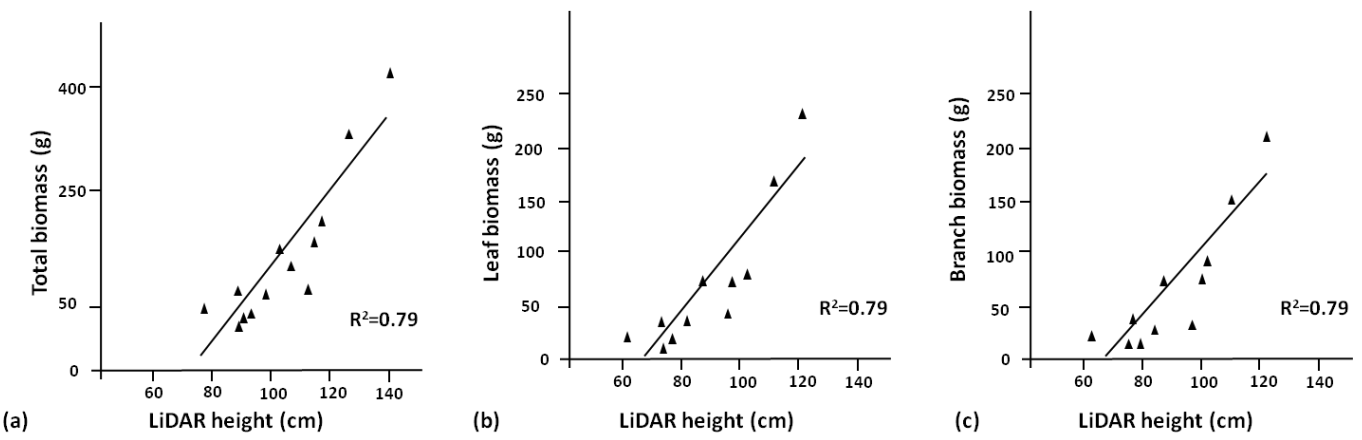

Fig. 4. Regression plot of tree height estimated by the LiDAR sensor versus tree biomass:

a) total tree biomass, b) leaf biomass and c) branch biomass.

Comparison between LiDAR reconstruction from the point cloud and actual tree shape architecture looked of high fidelity. Thus, the estimated tree volume was properly calculated and its relationship with biomass was highly accurate (Figure 5). Figure 5a shows the good estimation of total tree biomass, $R^{2}=0.89$. Similar to this study, Palacín et al. (2006) employed a TLS in pear trees and demonstrated that the relationship between the volume and the foliage can be interpreted linearly, and the foliar surface can be estimated with an average error less than 5\%. In addition, leaves and branch biomass showed a high correlation respect to the LiDAR estimated volume. This effect makes the tool a good approach for biomass estimation at harvest time. Since measurements were taken from a non-defoliated tree and branch biomass estimation was correct, the LiDAR sensors arise as a promising tool to evaluate poplar branch biomass at any time.
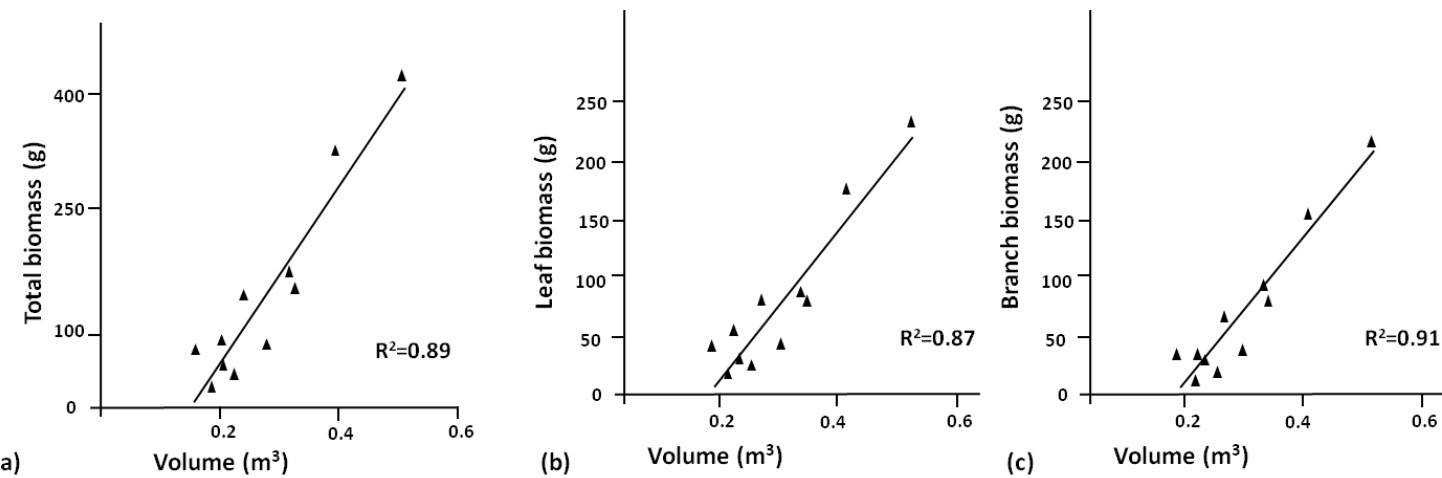

Fig. 5. Regression plot of tree volume estimated by the LiDAR sensor versus tree biomass: a) total tree biomass, b) leaf biomass and c) branch biomass. 
This is a pre-print version of the article A LiDAR-Based System to Assess Poplar Biomass published at the journal Gesunde Pflanzen on September 2016 at Volume 68, Issue 3, pp 155162 , with DOI 10.1007/s10343-016-0369-1. The final version of the article can be found at the publisher's website, Springer Link: https://link.springer.com/article/10.1007\%2Fs10343-0160369-1. Please, cite properly.

Consequently, these results suggest that the 3D tree model obtained from the LiDARbased system is accurate enough for poplar characterization. However, there are some problems inherent to laser measurements, such as the effect of occlusion, range and divergence of the laser beam. The 3D model created along the row reduced the effect of occlusion and non-visible parts can be detected and registered in the point cloud. The continuous scanning allowed to create a 3D map of the field with accuracy. In figure 1, it is possible to see the microrelief and the vehicle track along the row. Although the system provide fast, reliable, and non-destructive estimates of 3D crop structure, further experiments should be developed to establish the relationship with biomass production and its implication in crop management during various growing seasons.

\section{Conclusions}

According to the results obtained in our study, the LiDAR-based system is capable of obtaining the three-dimensional structure of trees. These results collected under field conditions allow constructing 3D digitised images of the poplar plantation, from which a large amount of plant information, such as height, width, and volume can be estimated. This information is useful for determining crop management practices, such as irrigation, fertilization or yield estimation before harvesting. In addition, the good branch estimation allowed by the system makes readings a good tool to estimate the final yield even when trees have plenty of leaves.

\section{Acknowledgements}

This research was funded by the CICyT (Commision Interministerial de Ciencia y Tecnología, Spain), under Agreement No. AGL2011-25243 and AGL2014-52465-C4.

\section{References}


This is a pre-print version of the article A LiDAR-Based System to Assess Poplar Biomass published at the journal Gesunde Pflanzen on September 2016 at Volume 68, Issue 3, pp 155162 , with DOI 10.1007/s10343-016-0369-1. The final version of the article can be found at the publisher's website, Springer Link: https://link.springer.com/article/10.1007\%2Fs10343-0160369-1. Please, cite properly.

Andújar D, Escolà A, Rosell-Polo JR, Fernández-Quintanilla C, Dorado J (2013) Potential of a terrestrial LiDAR-based system to characterize weed vegetation in maize crops. Comput Electron Agr 92: 11-15.

Andújar D, Ribeiro A, Fernández-Quintanilla C, Dorado, J (2011) Accuracy and feasibility of optoelectronic sensors for weed mapping in wide row crops. Sensors 11: 2304-2318.

Börjesson P (1999) Enviromental effects of energy crop cultivation in Sweden - part I: identification and quantification. Biomass Bioenergy 16: 137-154.

Cescatti A (2007) Indirect estimates of canopy gap fraction based on the linear conversion of hemispherical photographs - Methodology and comparison with standard thresholding techniques. Agr Forest Meteorol 143: 1-12.

Crimmins MA, Crimmins TM (2008) Monitoring plant phenology using digital repeat photography. Environ Manage 41: 949-958.

Dassot M, Baracci A, Colin A, Fournier M, Constant T (2010) Tree architecture and biomass assessment from terrestrial LiDAR measurements: a case study for some Beech trees (Fagus sylvatica). In: Proceedings of Silvilaser pp 206-215

Diago MP, Correa C, Millán B, Barreiro P, Valero C, Tardaguila J (2012) Grapevine yield and leaf area estimation using supervised classification methodology on RGB images taken under field conditions. Sensors 12: 16988-17006.

Gil E, Llorens J, Llop J, Fàbregas M (2013) Use of a terrestrial lidar sensor for drift detection in vineyard spraying. Sensors 13: 516-534.

Henning J, Radtke P (2006) Detailed stem measurements of standing trees from groundbased scanning lidar. Forest Sci, 52(1):67-80.

Hunt ER, Cavigelli M, Daughtry CST, Mc Murtrey JE, Walthall CL (2005) Evaluation of digital photography from model aircraft for remote sensing of crop biomass and nitrogen status. Precis Agric 6: 359-378.

Keightley K, Bawden G (2010) 3D volumetric modeling of grapevine biomass using tripod LiDAR. Comput Electron Agr 74: 305-312.

Llorens J, Gil E, Llop J, Escola A (2011) Ultrasonic and LiDAR sensors for electronic canopy characterization in vineyards: Advances to improve pesticide application methods. Sensors 11: 2177-2194. 
This is a pre-print version of the article A LiDAR-Based System to Assess Poplar Biomass published at the journal Gesunde Pflanzen on September 2016 at Volume 68, Issue 3, pp 155162 , with DOI 10.1007/s10343-016-0369-1. The final version of the article can be found at the publisher's website, Springer Link: https://link.springer.com/article/10.1007\%2Fs10343-0160369-1. Please, cite properly.

Mirtich B (1996) Fast and Accurate Computation of Polyhedral Mass Properties. Journal of graphics tools 1(2): 1-15.

Moorthy I, Miller JR, Berni, JAJ, Zarco-Tejada P, Hu B, Chen J (2011) Field characterization of olive (Olea europea L.) tree crown architecture using terrestrial laser scanning data. Agr. Forest. Meteorol. 151: 204-214

Palacín J, Salse JA, Sanz R, Ribes-Dasi A, Masip J, Arnó J, Llorens J, Vallés JM. Escolà A, Massana P, Camp F, Solanelles F, Rosell JR (2006) Real-Time tree foliage estimation using a ground laser scanner. instrumentation and measurement. IEEE Transactions 56: 1377-1383.

Pérez-Cruzado C, Sanchez-Ron D, Rodríguez-Soalleiro R, Hernández MJ, SánchezMartín MM, Cañellas I, Sixto H (2014) Biomass production assessment from Populus spp. short-rotation irrigated crops in Spain. GCB Bioenergy 6: 312-326.

Richardson JJ, Moskal LM, Kim SH (2009) Modeling approaches to estimate effective leaf area index from aerial discrete-return LiDAR. Agr Forest Meteorol 149: 11521160 .

Rosell JR, Sanz R (2012) A review of methods and applications of the geometric characterization of tree crops in agricultural activities. Comput Electron Agr 81: $124-141$.

Rosell JR, Llorens J, Sanz, R, Arno J, Ribes-Dasi M, Masip J, Escolà A, Camp F, Solanelles F, Gràcia F, Gracia F, Gil E, Val L, Plans S, Palacin J (2009a) Obtaining the three-dimensional structure of tree orchards from remote 2D terrestrial LIDAR scanning. Agr. Forest. Meteorol. 149: 1505-1515.

Rosell JR, Sanz R, Llorens J, Arno J, Escolà A, Ribes-Dasi M, Masip J, Camp F, Gràcia F, Solanelles, F, Gracia F, Solanelles F, Palleja T, Val L, Planas S, Palacin J (2009b) A tractor-mounted scanning LIDAR for the non-destructive measurement of vegetative volume and surface area of tree-row plantations: A comparison with conventional destructive measurements. Biosyst Eng 102, 128-134

Saeys W, Lenaerts B, Craessaerts G, De Baerdemaeker J (2009) Estimation of the crop density of small grains using LiDAR sensors. Biosyst Eng 102: 22-30.

Tremblay N, Wang Z, Ma BL, Belec C, Philippe P (2009) A comparison of crop data measured by two commercial sensors for variable-rate nitrogen application. Precis Agric 10: 145-161. 
This is a pre-print version of the article A LiDAR-Based System to Assess Poplar Biomass published at the journal Gesunde Pflanzen on September 2016 at Volume 68, Issue 3, pp 155162 , with DOI 10.1007/s10343-016-0369-1. The final version of the article can be found at the publisher's website, Springer Link: https://link.springer.com/article/10.1007\%2Fs10343-0160369-1. Please, cite properly.

Walklate P, Cross J, Richardson G, Baker D (2006) Optimising the adjustment of labelrecommended dose rate for orchard spraying. Crop Prot 25: 1080-1086.

Wang Q, Nuske S, Bergerman M, Singh S (2013) Automated crop yield estimation for apple orchards. Experimental Robotics 88: 745-758.

Weis M, Sökefeld M (2010) Precision farming for weed management: techniques. Gesunde Pflanz 60: 171-181

Yamamoto K, Guo W, Yoshioka Y, Ninomiya S (2014) On plant detection of intact tomato fruits using image analysis and machine learning methods. Sensors 14: 12191-12206.

Zaman Q, Schumann A, Percival D, Read S, Esau T, Farooque A (2011) Development of cost-effective prototype variable rate sprayer for spot-specific application of agrochemicals in wild blueberry cropping systems. Comput Electron Agr 76: 175182. 